\title{
Performance of Liquids from Slow Pyrolysis and Hydrothermal Carbonization in Plant Protection
}

\author{
Marleena Hagner $^{1,2} \cdot$ Kari Tiilikkala $^{1} \cdot$ Isa Lindqvist ${ }^{1} \cdot$ Klaus Niemelä $^{3} \cdot$ Hanne Wikberg $^{3,4} \cdot$ Anssi Källi $^{3} \cdot$ Kimmo Rasa $^{1}$
}

Received: 30 July 2018 / Accepted: 14 December 2018 / Published online: 19 December 2018

(c) The Author(s) 2018

\begin{abstract}
The feasibility of thermochemical biomass conversion technologies can be improved if value-added applications for all fractions can be developed. One of such approaches is the use of liquid by-products from slow pyrolysis and hydrothermal carbonization (HTC) in plant protection. Liquids produced from slow pyrolysis of pine bark, pine forest residues, wheat straw, and willow, and from hydrothermal carbonization of willow, were analyzed in this study. In particular, potential active compounds were analyzed, covering the main volatile, simple organic compounds and numerous phenolic substances. Effectivity tests of the liquids as pest repellent (Arianta arbustorum), herbicide (Brassica rapa), and insecticide (Rhopalosiphum padi) indicated that slow pyrolysis liquid from willow was the most effective pesticide, followed by the liquid from wheat, bark, and forest residues. HTC liquid did not show any pesticidal activity due to low concentration of organic compounds. High content of acetic acid and other carboxylic acids, and the presence of dozens of different phenolic compounds seem to be the main reason for the higher pesticidal activity of willow-derived pyrolysis liquid. Temperature-separated slow pyrolysis liquids proved to be suitable to be used as pesticides. Consequently there is possibility to improve the feasibility of thermochemical biomass conversion technologies remarkably by developing the liquid factions to value-added pesticides.
\end{abstract}

\section{Graphical Abstract}

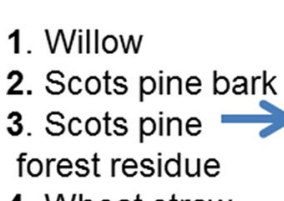

4. Wheat straw

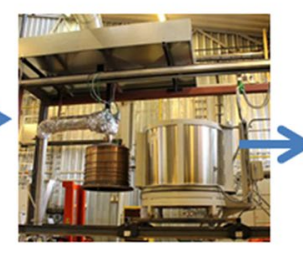

Slow pyrolysis / HTC

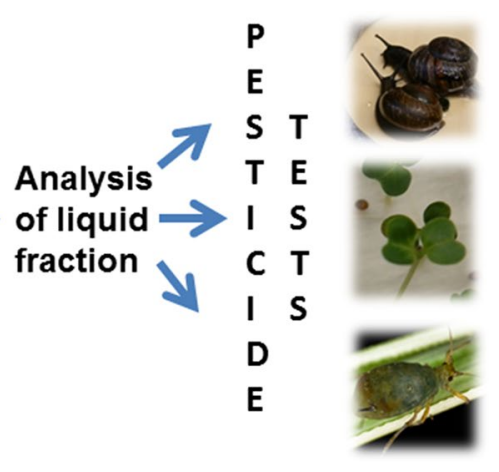

Keywords Pine $\cdot$ Wheat straw $\cdot$ Willow $\cdot$ Slow pyrolysis $\cdot$ Hydrothermal carbonization $\cdot$ Pyrolysis liquids $\cdot$ Plant protection

Marleena Hagner

marleena.hagner@luke.fi

Extended author information available on the last page of the article

\section{Statement of Novelty}

The environmental sustainability and industrial exploitation of thermochemical conversion technologies are strongly dependent on whether all the produced fractions produced can be utilized reasonably. Effective practices have not yet been devised for liquid fraction and therefore new and well-documented ways to utilize these liquids are needed. 
Potential of various pyrolysis and HTC liquids as pest repellent (Arianta arbustorum), herbicide (Brassica rapa), and insecticide (Rhopalosiphum padi) were studied. The potential compounds having pesticidal activity were analyzed. Slow pyrolysis liquid from willow (WI-PL) was the most effective pesticide followed by the liquid from wheat (WHPL), bark (BP-PL), and forest residues (FR-PL). Instead, HTC liquid (HTC-L) did not show any pesticidal activity. Content of acids explains the most differences in pesticidal activities. Selection of raw material and technology will determine the quality of liquids and potential to commercialize these products.

\section{Introduction}

In recent years, thermochemical conversion technologies such as torrefaction, slow pyrolysis, and hydrothermal carbonization (HTC) have gained increasing interest in converting various types of biomass to energy and carbonaceous end-products [1,2]. Slow pyrolysis is an energy-efficient and robust process that produces high yields of solid biochar from biomass in an inert atmosphere at elevated temperatures $\left(\sim 300-650{ }^{\circ} \mathrm{C}\right)$. In addition to solid biochar, the process yields liquid and gaseous products that can be either partly or fully utilized as energy sources at the production site. In HTC, wet biomass at approximately $10-20 \%$ consistency is converted to biochar under pressure (typically $<50$ bar) at moderate temperatures (approx. $180-260{ }^{\circ} \mathrm{C}$ ), using water as the carbonization medium. As a result, a solid carbonaceous biochar (often referred as hydrochar), a liquid phase consisting of small degradation products, and a minor gas phase are formed. In general, thermochemical conversion technologies are flexible with respect to raw materials and produces solid, liquid, and gaseous end-products of varying quality and quantity. Biochar in particular has recently attracted wide interest because of its potential benefits in agronomic applications, especially improving soil fertility and carbon sequestration [2]. Depending on feedstock material and processing conditions, the chemical composition of products from thermochemical conversion processes can vary significantly. Typically, lignocellulosic biomass comprises 20-30\% hemicellulose, 40-50\% cellulose, and 10-25\% lignin. During the thermochemical processing of plant constituents, hemicelluloses are degraded in the temperature range $180-260^{\circ} \mathrm{C}$, cellulose at $240-350{ }^{\circ} \mathrm{C}$, and lignin at $280-500{ }^{\circ} \mathrm{C}$ [3]. The resulting liquids contain e.g., a wide range of organic compounds such as acetic acid, furfural, and phenolics [3-5]. In HTC and slow pyrolysis, various chemical reactions occur when processing heterogeneous biomass. The composition of the liquid fraction is hence highly dependent on the feedstock composition, the thermal conversion technology used, and process conditions (especially temperature) $[2,5]$. Consequently, appropriate analytical procedures to characterize these liquids are of great importance when assessing the functionality of these products in various applications.

The overall feasibility, environmental sustainability, and industrial exploitation of thermochemical conversion technologies are strongly dependent on whether all the fractions produced can be utilized reasonably. There are various alternative ways to utilize these liquids, e.g., Keskinen et al. [6] suggest use of temperature-fractionated slow pyrolysis liquids for manure acidification. Other researchers suggest separation of the liquids into fractions of specific compounds [7-9]. One of the potential ways to get added value for the liquid fractions is their use for plant protection purposes [5, 10]. However, effective practices have not yet been devised and therefore new and well-documented ways to their utilization are strongly needed.

In the European Union (EU), there is a generally recognized need to develop alternatives to replace certain groups of pesticides which have been questioned in integrated pest management (IPM) (2009/128/EC). Such pesticides include a broad spectrum of organophosphates, carbamates, and neonicotinoids. Use of slow pyrolysis liquids (pyroligneous acids) as herbicides, insecticides, and fungicides has a long tradition in many Asian countries [11-13]. Recent studies suggest that pyrolysis liquids are effective against a number of pests [10-12, 14]; exert antifungal activity against pathogenic fungi and yeasts $[15,16]$; and induce systemic resistance to fungal diseases in plants [17]. However, more scientific evidence is needed concerning the effectiveness of liquids from various feedstocks and thermochemical conversion technologies (processes and conditions) in various applications and under controlled study conditions.

As the chemical composition of the liquids from slow pyrolysis and HTC varies significantly, their effectiveness as a pesticide may also differ. Hossain et al. [11] found that lignin-based pyrolysis liquids (aquatic and organic phase bio-oils) produced at higher temperatures $\left(550{ }^{\circ} \mathrm{C}\right)$ were more toxic to the larvae of Colorado beetle (Leptinotarsa decemlineata) than those produced at lower temperatures $\left(450{ }^{\circ} \mathrm{C}\right)$ and concluded that polycyclic aromatic hydrocarbons (PAHs) are probably the principal compounds responsible for the observed insecticidal activity of ligninbased pyrolysis liquids. Hagner et al. [10] found that birch (Betula sp.)-derived slow pyrolysis liquids containing PAH substances can repel snails (Arianta arbustorum). As the PAH compounds are ubiquitous environmental pollutants with toxic, mutagenic, and carcinogenic effects on various organisms, their release into the environment is highly restricted [18]. Fagernäs et al. [19, 20] suggest that, due to their low tar and PAH content, pyrolysis liquids separated out at below $300{ }^{\circ} \mathrm{C}$ are most promising to commercialize for various applications. Recent technical development has 
led to new innovations targeting in situ separation of lowand high-temperature pyrolysis liquids (continuous pyrolysis device, ongoing patenting), which could facilitate utilization of pyrolysis liquids [5, 6]. Thus more studies are required to optimize feedstock materials, pyrolysis conditions, and liquid collection set-ups to produce various slow pyrolysis liquids without carcinogenic PAHs and with well-documented functionality in various usages.

The aim of the present study was to determine the pesticidal efficacy of various PAH-free liquids from slow pyrolysis of pine bark (PB-PL), pine forest residues (FR-PL), wheat straw (WH-PL), willow (WI-PL), and from hydrothermally carbonized willow (HTC-L). The effect of the liquids as a (i) repellent, using the copse snail (Arianta arbustorum), (ii) herbicide, using turnip rape seedlings (Brassica rapa), and (iii) insecticide against aphids (Rhopalosiphum padi) was tested at laboratory scale. An additional aim was to characterize the liquids in terms of potential bioactive compounds inducing pesticidal impacts including the main volatile, simple organic compounds and phenolic substances.

\section{Materials and Methods}

\section{Feedstock and Process Conditions}

The feedstocks used as raw materials for thermochemical conversion were Scots pine bark, Scots pine forest residues (composed of small trees with twigs and needles), wheat straw, and willow (Salix sp., unbarked short rotation coppice). Prior to processing, the raw materials were dried at $<70{ }^{\circ} \mathrm{C}$ in a flat-bed drying wagon to a dry matter content of approximately $90 \%$ (w/w) (Table 1) and thereafter shredded in a single-shaft shredder with a $15-\mathrm{mm}$ screen. The four pyrolytic treatments were conducted in a batch-type bench-scale slow pyrolysis unit where the reactor is indirectly heated with an electric oven. The pyrolysis unit and its operations have been described in detail, together with a photo on its layout, by Fagernäs et al. [20]. The capacity of the reactor was about $6 \mathrm{~kg}$ for feedstock. The temperature of the oven was controlled via a preset program to pass through multiple steps. In practice, the rate of temperature rise was approximately $8{ }^{\circ} \mathrm{C} \mathrm{min}{ }^{-1}$. Liquid samples for further testing were collected at reactor temperatures below $280{ }^{\circ} \mathrm{C}$, to obtain liquids with a high content of organic acids and a low content of tars. After collection of the acidic liquids (used in this study), the pyrolysis process was continued to reach the target temperatures $\left(375\right.$ and $\left.475^{\circ} \mathrm{C}\right)$ for the production of tar-rich liquid fraction (derived $>280{ }^{\circ} \mathrm{C}$ ) and biochar. The results of tar-rich liquid fraction and biochar will be published elsewhere.

The HTC treatment (willow only) was carried out in a 10-L Hastelloy C276 stirred autoclave reactor (see Wikberg et al. [21]). The process sequence consisted of reactor heating up to $260{ }^{\circ} \mathrm{C}$ ( $\left.60 \mathrm{~min}\right)$, residence time of $6 \mathrm{~h}$, and a water cooling period before venting the residual pressure and opening the reactor. Four sequential runs were performed while recycling the liquid fraction to make it more concentrated. First, willow-water suspension with a consistency of approximately $4 \%(\mathrm{w} / \mathrm{w})$ was introduced to the reactor. Very low consistency was used to ensure that the mixing in the reactor would work during HTC processing. After the treatment, the carbonaceous slurry was filtered in a Büchner funnel and the liquid was collected for reuse. For preparation of the willow-water suspension for subsequent runs, approximately $7100 \mathrm{~g}$ of the recycled liquid were combined with $400 \mathrm{~g}$ of de-ionized water, and then mixed with around $310 \mathrm{~g}$ of dried willow chips. After the fourth repetition, the final liquid was collected for the study. Further information about the materials and process conditions is given in Table 1. The same raw-materials and processing conditions were previously used in the study of Keskinen et al. [6].

Altogether, five different liquid fractions were produced: slow pyrolysis liquids originating from pine bark

Table 1 Properties of feedstock materials and process conditions used to produce slow pyrolysis liquids based on pine bark (PB-PL), forest residues (FR-PL), wheat straw (WH-PL), and willow (WI-PL), and hydrothermal carbonization (HTC) liquid from willow (HTC-L)

\begin{tabular}{|c|c|c|c|c|c|}
\hline & PB-PL & FR-PL & WH-PL & WI-PL & HTC-L \\
\hline Feedstock & Scots pine bark & Forest residue & Wheat straw & Willow & Willow \\
\hline Process & Slow pyrolysis & Slow pyrolysis & Slow pyrolysis & Slow pyrolysis & HTC \\
\hline Process temperature ${ }^{\circ} \mathrm{C}$ & 280 & 280 & 280 & 280 & 260 \\
\hline Moisture $\%(\mathrm{wt})$ of feedstock ${ }^{\mathrm{a}}$ & 7.8 & 7.3 & 6.4 & 5.6 & $5.6^{\mathrm{b}}$ \\
\hline Ash content $\%(w t)$ dry matter ${ }^{c}$ & 2.3 & 2.0 & 8.2 & 1.9 & 1.9 \\
\hline Volatile matter $\%(w t)$ dry matter ${ }^{d}$ & 74.3 & 78.1 & 75.1 & 80.5 & 80.5 \\
\hline
\end{tabular}

${ }^{\mathrm{a}}$ EN 14774-1

${ }^{b}$ In the HTC process, the feedstock was mixed with water and the final moisture content of Salix sp.+ water suspension was $96 \%$

${ }^{\mathrm{c}} \mathrm{ISO} 18122$

${ }^{\mathrm{d}}$ EN ISO 18123 
(PB-PL), forest residues (FR-PL), wheat (WH-PL), and willow (WI-PL), and recycled HTC liquid from willow (HTC-L).

\section{Analysis of the Liquids}

Organic compounds in the liquid samples were analyzed by gas chromatography (GC), using separate methods for different compound types. The most volatile compounds were analyzed directly in the aqueous samples, as described by Lindfors et al. [22] and Fagernäs et al. [20], using a flame ionization detector and an Innowax capillary column. The aromatic compounds were analyzed by gas chromatography-mass spectrometry (GC/MS) after trimethylsilylation, using a method slightly modified from that of Borrega et al. [23]. In an earlier study, the same liquids were analyzed by capillary electrophoresis for volatile fatty acids and other simple carboxylic acids [6].

For trimetylsilylation, the aromatic compounds were extracted twice from the liquids $(1-3 \mathrm{~mL})$ with $4-5 \mathrm{~mL}$ of diethyl ether, after addition of salicylic acid as the internal standard. The organic phases were evaporated to dryness and derivatized in pyridine $(0.2 \mathrm{~mL})$ with a $0.2 \mathrm{~mL}$ mixture (3:1) of $\mathrm{N}, \mathrm{O}$-bis(trimethylsilyl)trifluoroacetamide and trimethylchlorosilane. The GC/MS runs were performed with an Agilent 6890 series GC system, equipped with an Agilent 5973 mass selective detector and a DB-5 MS capillary column $(30 \mathrm{~m} \times 0.25 \mathrm{~mm}$, film thickness $0.25 \mu \mathrm{m})$. The temperature program applied was $1 \mathrm{~min}$ at $70{ }^{\circ} \mathrm{C}, 10{ }^{\circ} \mathrm{C} \mathrm{min}-1$ to $300{ }^{\circ} \mathrm{C}$, and $11 \mathrm{~min}$ at $300{ }^{\circ} \mathrm{C}$. The injection split ratio was 50:1. The MS identifications were based on the use of relevant literature $[23,24]$ an in-house MS library, and the commercial Wiley database. Quantitative determinations were based on peak areas without corrections.

The liquid samples were analysed (Fagernäs et al. [19]) by Eurofins Nab Labs Ltd (Finland) for 16 PAH compounds usually monitored by the US Environmental Protection Agency EPA. For this, 2-g liquid samples were extracted with hexane, after addition of four deuterated PAH compounds (naphthalene-d8, anthracene-d10, chrycene-d12 and dibenzo[a,h]anthracene-d14) as internal standards. The extracts were further cleaned by DMSO liquid-liquid partitioning and subjected to the SIM mode GC/MS analysis. The runs were performed with an Agilent 5973 GC/MS system, equipped with an HP-5MS capillary column $(25 \mathrm{~m} \times$ $0.2 \mathrm{~mm}$, film thickness $0.33 \mu \mathrm{m})$. The temperature program applied was $1 \mathrm{~min}$ at $60{ }^{\circ} \mathrm{C}, 8{ }^{\circ} \mathrm{C} \mathrm{min}{ }^{-1}$ to $300{ }^{\circ} \mathrm{C}$, and $10 \mathrm{~min}$ at $300^{\circ} \mathrm{C}$. The splitless injection technique was used. The detection limit for this method is $0.1 \mu \mathrm{gL}^{-1}$ sample and the repeatability $\pm 20-40 \%$, depending on the concentrations of the individual components.

\section{Repellent Experiments}

Protocol developed by Lindqvist et al. [14] was used to test the repellent effect of the five liquids on common garden snails (Arianta arbustorum). Adult snails were collected from a fertile grove in Jokioinen, Southern Finland, on the evening before the test day and placed in a refrigerator $\left(+4{ }^{\circ} \mathrm{C}\right)$. Maturity of snails was ensured by identifying the thickened outer lip framing the aperture of the shell [25]. The snails were collected on the previous evening of the testing day and placed in a refrigerator $\left(+4{ }^{\circ} \mathrm{C}\right)$ prior to testing. The snails were taken into room temperature $\left(20-22{ }^{\circ} \mathrm{C}\right) 15 \mathrm{~min}$ before the tests and individuals that woke within $15 \mathrm{~min}$ were selected and immediately used in the experiments. As snails can sense and be disturbed even by extremely small concentrations of the test liquids, the tests were conducted in the three separate rooms during 1 week. The slow pyrolysis and HTC-L liquidwere tested in $10 \%$ and $1 \%(\mathrm{v} / \mathrm{v})$ concentrations, with each treatment having four replicates. HTC-L was also tested in $20 \%$ concentration. In addition, commercial BioPlantella snail gel (Unichem d.o.o.), a commercial product known to repel snails, was used as an active control. The BioPlantella and water controls (without additions) were replicated every testing day, i.e., each liquid and concentration tested had a separate control treatment.

The test arenas were constructed from circular plastic rings (outer $\varnothing 10.5 \mathrm{~cm}$, inner $\varnothing 6.5 \mathrm{~cm}$, height $2.5 \mathrm{~cm}$ ), which were placed in the test dilutions and left to saturate for $30 \mathrm{~s}$. The rings were immediately placed on a plastic base and two snails were positioned in the middle of each ring. The distance between the test units (plastic rings) was around $20 \mathrm{~cm}$. Leaves of lettuce were placed outside the rings to lure the snails to leave the ring. The escape time of snails, i.e., the time between positioning the snail in the middle of the ring and recording it (1) on the rim and (2) fully outside the ring was observed during $60 \mathrm{~min}$. Snails that left the rings were removed from the experimental area.

\section{Herbicidal Effects}

The herbicidal effect of the pyrolysis liquids on turnip rape (Brassica rapa: Apollo, Boreal Plant Breeding Ltd) was tested using the Jacobsen germinator (Rubart Apparate $\mathrm{GmBH}$ ) [26]. It consists of a germination plate that is temperature-conditioned by means of a water basin below. Germination spirals (filter papers $\varnothing 6 \mathrm{~cm}$ ) equipped with a paper wick and a paper substrate were placed on the germination plate. The wick was led through slots in the germination plate and into the water bath below, thus supplying the required humidity and desired temperature $\left(20^{\circ} \mathrm{C}\right)$ to the paper substrate. Turnip rape seeds ( $20 \mathrm{pcs})$ were placed on germination spirals, which were covered with a transparent 
cover dome to provide the air humidity required for germination. A little hole in the upper end of the dome ensured a sufficient supply of fresh air and minimum evaporation. After 7 days, the covers were removed, the germinated seedlings were counted, and the germination spirals with seedlings were treated with liquid dilutions. Tap water was used as an inert control and 2-methyl-4-chlorophenoxyacetic acid (MCPA, $0.5 \mathrm{~mL} \mathrm{~L}^{-1}$ ) and Cooper (acetic acid $240 \mathrm{~g} \mathrm{~L}^{-1}$, Berner Oy) were used as active controls. An even deposit of distillate over the filter paper was achieved using a Potter precision laboratory spray tower spraying $0.6 \mathrm{~mL}$ of the selected liquid per filter paper. The liquid concentrations tested were 100, 40, 30, and 20\% (v/v) The tests started with the highest concentration of each liquid. If the liquid damaged $>60 \%$ of seedlings, it was included the next test with more dilute solution. All treatments had four replicates and each concentration had its own controls (water, Cooper, and MCPA). The treated germination spirals were returned to the Jacobsen germinator and the cover domes were set on their places. The number of living seedlings and the weight of their wet biomass (without primary seed) were measured after 7 days.

\section{Aphid Dip Bioassay}

A greenhouse strain of aphids (Rhopalosiphum padi) from Biotus Oy has been propagated in Natural Resources Institute Finland since 2015. The colony is maintained in a growth chamber with growing barley (strain Voitto) as a food source at $27 \pm 5^{\circ} \mathrm{C}$, under continuous light $(24 \mathrm{~h})$. The condition of aphids is checked and a new pot of barley is added weekly. A protocol was developed in this study for dipping aphids in liquid solution. Barley leaves $(3 \mathrm{~cm})$ containing around 10-15 aphids were cut from plants growing in the growth chamber and dipped immediately for $2 \mathrm{~s}$ in $20 \mathrm{~mL}$ of tap water (a pure control treatment), Sumi-Alpha (esfenvalerate $50 \mathrm{~g} \mathrm{~L}^{-1}$, a commercial control which killed all aphids), or experimental liquid. After $2 \mathrm{~s}$, the leaf with aphids was transferred from the solution and blotted in a clean bowl $(30 \mathrm{~mL})$. The bowls were closed using perforated lids with a $0.7 \mathrm{~cm} \varnothing$ hole covered with gauge and held in continuous light in a water steam (to maintain humidity) in a growth chamber at $22{ }^{\circ} \mathrm{C}$. After $24 \mathrm{~h}$, a fresh $3 \mathrm{~cm}$ barley leaf was added to each bowl. After another $24 \mathrm{~h}$, the aphids were counted and classified as dead, knockdown (lying upside down and moving their legs), or alive. The slow pyrolysis liquid concentrations tested were 100, 50, 40, 25, 20, 15, 10, and $5 \%(\mathrm{v} / \mathrm{v})$, with each treatment having four replicates. Tests were first conducted with $100 \%$ liquids, and solutions eliminating $>80 \%$ of aphids were included in the next test with more dilute liquids. This protocol resulted in aphid survival of $\geq 95 \%$ after $48 \mathrm{~h}$ in controls receiving water only, indicating that the aphid-dip method was reliable for conducting the bioassays.

\section{Statistical Analysis}

The normality of data was analyzed using the Kolmogorov-Smirnov and Shapiro-Wilk tests and the homogeneity of variances with Levene's test. The data were not always normally distributed and the variances were sometimes heterogeneous, so when needed, transformations (log) were used to normalize data. First, the similarity of control treatments (snails: water only and BioPlantella; turnip rape: water only, MCPA, and Cooper; aphids: water only and Sumi-Alpha) conducted during various days was tested by one-way ANOVA. The Tukey post hoc test was used for paired comparisons. As there were no differences in the repellent effect of controls conducted on separate days, the data from all treatments were combined and analyzed as follows:

The repellent effect on snails was analyzed using repeated measures ANOVA. Response variables were: (1) placing snails in the ring (mean of two snails per ring) and (2) snails outside the ring. Treatments (water only, BioPlantella, PB-PL, FR-PL, WH-PL, WI-PL, and HTC-L) were used as predictor variables. Data concerning the herbicidal effect of various liquids on turnip rape seedlings were not normally distributed even after transformation and were therefore analyzed using the non-parametric Kruskall-Wallis test. The Mann-Whitney $U$ test was used for paired comparisons, using treatment as predictor variable and observed effect (number of dead/healthy seedlings and biomass) as response variable. Results of aphid experiments were analyzed using one-way ANOVA. Percentages of dead and knockdown aphids were used as response variable and treatment as predictor variable. In all tests the concentrations were analyzed separately.

Regression analysis (step-wise model) was used to analyze the correlation between the concentrations of various chemicals in slow pyrolysis liquids and observed responses on test organisms: snails on the rim and outside the ring ( $1 \%$ liquids), number of dead/healthy seedlings and biomass of turnip rape ( $40 \%$ liquids), and percentages of dead and knockdown aphids (40\% liquids). The highest pyrolysis liquid concentration showing statistically significant differences between products was chosen as the test concentration.

\section{Results and Discussion}

\section{Composition of the Liquids}

In the GC and GC/MS analyses, more than 200 low-molar mass compounds were detected in the liquid samples. A 
significant proportion of these were either fully or partly identified, although only limited attention was paid to compounds present in trace amounts $\left(<5-10 \mathrm{mg} \mathrm{L}^{-1}\right)$. Most of the compounds identified represent known products from pyrolysis, dry distillation, or torrefaction of various lignocellulosic biomasses [20, 27-29], including slow pyrolysis of pine bark [30], forest residues [31], and willow [32]. However, some novel or uncommon pyrolytic products were also detected.

The water content of raw-material influences its behavior during pyrolysis and affects the quality of the produced pyrolysis liquid. Thus we aimed at drying all feedstock materials to similar initial levels before thermochemical processing; the moisture content of raw-materials varied only slightly being between 5.6 and $7.8 \%$ (Table 1). However, the variation in the water content of the produced liquids (PBPL, FR-PL, WH-PL, WI-PL, and HTC-L) was much higher being 87.2, 81.5, 74.6, 69.6, and $97.6 \%(\mathrm{w} / \mathrm{w})$, respectively. Consequently, at least when water content of feedstock materials is low, the water producing reactions occurring during the thermochemical conversion of organic material have higher impact on the water content of the produced liquids than small differences in the moisture content of feedstock materials. As assumed, the most abundant volatile aliphatic compound in each liquid was acetic acid, most of which is derived from slow pyrolysis of acetylated hemicelluloses. The highest acetic acid concentration was found in slow pyrolysis liquid derived from willow (WI-PL, $162 \mathrm{~g} \mathrm{~L}^{-1}$ ), followed by wheat straw-based liquid (WH-PL, $84 \mathrm{~g} \mathrm{~L}^{-1}$ ) and liquid from Scots pine forest residues (FR-PL $67 \mathrm{~g} \mathrm{~L}^{-1}$ ) and bark (PB-PL $44 \mathrm{~g} \mathrm{~L}^{-1}$ ) (Table 2). These concentration differences are well in line with the known higher acetyl content of hardwood and agro-based materials compared with softwood [33]. In comparison, the acetic acid concentration in the willow-based HTC liquid (HTC-L) was only $9.4 \mathrm{~g} \mathrm{~L}^{-1}$. Other major compounds in the slow pyrolysis liquids included methanol (15-21 $\mathrm{g} \mathrm{L}^{-1}$ ), hydroxyacetone (8.2-19 $\left.\mathrm{g} \mathrm{L}^{-1}\right)$, 1-hydroxy-2-butanone (1.3-11 $\left.\mathrm{g} \mathrm{L}^{-1}\right)$, formic acid (4.3-7 $\left.\mathrm{g} \mathrm{L}^{-1}\right)$, and propanoic acid $\left(2.8-9.6 \mathrm{~g} \mathrm{~L}^{-1}\right)$. Corresponding concentrations in HTC-L were 1.9, 0.1, 0.01, 0.1 , and $0.3 \mathrm{mg} \mathrm{L}^{-1}$, respectively (Table 2).

The aromatic compounds comprised complex mixtures of well-established lignin-derived phenolic compounds (Table 3). In many cases, similar guaiacyl and syringyl compounds were formed from the two main raw material types (in terms of their lignin structures). For the softwood-based raw materials, i.e., pine bark and forest residues (PB-PL and FR-PL), these mainly included different guaiacyl (4-hydroxy-3-methoxyphenyl) compounds and catechols (Table 3). One of the most striking differences was in the arylalkanols, as e.g., dihydroconiferyl alcohol was one of the main products in slow pyrolysis liquids originating from softwood, but only traces were found in
Table 2 Concentrations $\left(\mathrm{mg} \mathrm{L}^{-1}\right)$ of the most volatile compounds in the slow pyrolysis liquids based on pine bark (PB-PL), forest residues (FR-PL), wheat straw (WH-PL), and willow (WI-PL), and hydrothermal carbonization (HTC) liquid based on willow (HTC-L), as analyzed by GC-FID on an Innowax column, using direct injection of the aqueous samples

\begin{tabular}{lrrrrr}
\hline Compound & PB-PL & FR-PL & WH-PL & WI-PL & HTC-L \\
\hline Furan & 70 & 140 & 200 & 30 & 25 \\
Methanol & 17,300 & 21,000 & 15,000 & 20,100 & 1880 \\
Ethanol & 150 & 170 & 100 & 140 & 40 \\
2-Propanol & 940 & 330 & 150 & 100 & 50 \\
Acetaldehyde & 750 & 1050 & 880 & 330 & 60 \\
Glycolaldehyde & 690 & 1020 & 1500 & 1020 & 100 \\
Furfural & 3230 & 1270 & 530 & 1170 & 35 \\
5-Methylfurfural & 1560 & 680 & 160 & 790 & 10 \\
2-Acetylfuran & 310 & 260 & 330 & 490 & 80 \\
Acetone & 870 & 760 & 550 & 330 & 480 \\
Hydroxyacetone & 8200 & 14,900 & 18,600 & 14,700 & 95 \\
2-Butanone & 330 & 520 & 760 & 330 & 160 \\
1-Hydroxy-2-bu- & 1270 & 2980 & 11,300 & 5580 & 10 \\
tanone & & & & & \\
Formic acid & 4300 & 7000 & 4600 & 5300 & 100 \\
Acetic acid & 43,900 & 66,800 & 84,400 & 162,000 & 9390 \\
Propanoic acid & 2800 & 3690 & 9560 & 5470 & 310 \\
\hline
\end{tabular}

Formic acid data is from Keskinen et al. [5]

liquids originating from willow (WI-PL) and wheat (WHPL). In contrast, WI-PL and WH-PL contained a variety of syringyl (4-hydroxy-3,5-dimethoxyphenyl) compounds, but only traces were found in the softwood-based liquids (Table 3). Catechol was the main phenolic compound in all liquids tested. Although substantial amounts of the methylcatechols and 4-ethylcatechol were also present, the overall profiles of different catechol compounds were relatively simple (compared with the guaiacyl and syringyl compounds).

One of the catechol compounds deserves special attention due to its unexpected occurrence in moderate amounts in the samples. This compound was found in all liquids, with the highest concentrations in those from wheat and willow. It was finally identified as 3-(2,3-dihydroxyphenyl)propanoic acid with the help of a commercial model compound (Toronto Research Chemicals). The mass spectrum [m/z (\% rel. int), 398 (M+, 55), 383 (44), 293 (13), 253 (18), 193 (19), 179 (100), 147 (30), 73 (90)] is also in good agreement with data in Snook et al. [34] and Burlingame and Chapman [35]. To our knowledge, this catecholic carboxylic acid has not been found previously among the pyrolytic products of any lignocellulosic material. Other phenolic substances detected included phenol and its simple alkyl derivatives, 4-hydroxyphenyl compounds, and benzenediols other than catechols. 
Table 3 Indicative

concentrations $\left(\mathrm{mg} \mathrm{L}^{-1}\right)$ of the main aromatic compounds identified as their trimethylsilyl derivatives (with the exception of phenol analyzed by direct water injection) in the slow pyrolysis liquids based on pine bark (PB-PL), forest residues (FR-PL), wheat straw (WHPL), and willow (WI-PL), and hydrothermal carbonization (HTC) liquid based on willow (HTC-L)

\begin{tabular}{|c|c|c|c|c|c|}
\hline Compound & PB-PL & FR-PL & WH-PL & WI-PL & HTC-L \\
\hline Benzoic acid & 52 & 72 & 0 & 29 & 0 \\
\hline Phenol & 92 & 356 & 90 & 486 & 122 \\
\hline 2-Methylphenol & 15 & 32 & 22 & 58 & 0 \\
\hline 3-Methylphenol & 30 & 136 & 66 & 218 & 0 \\
\hline 4-Methylphenol & 15 & 104 & 77 & 131 & 0 \\
\hline Miscellaneous alkylphenols & 7 & 24 & 44 & 44 & 0 \\
\hline 4-Hydroxyacetophenone & 0 & 280 & 0 & 0 & 0 \\
\hline 4-Hydroxybenzoic acid & 0 & 72 & 0 & 0 & 22 \\
\hline 3-(4-Hydroxyphenyl)-1-propanol & 37 & 88 & 0 & 0 & 0 \\
\hline Guaiacol & 37 & 264 & 363 & 522 & 29 \\
\hline 4-Methylguaiacol & 111 & 232 & 121 & 174 & 0 \\
\hline 4-Ethylguaiacol & 22 & 32 & 121 & 160 & 0 \\
\hline 4-Propenylguaiacols (3 isomers) & 0 & 0 & 0 & 145 & 0 \\
\hline Vanillin & 222 & 160 & 220 & 319 & 0 \\
\hline Acetovanillone & 67 & 88 & 154 & 73 & 19 \\
\hline Guaiacylacetone & 111 & 272 & 176 & 261 & 15 \\
\hline Vanillic acid & 74 & 56 & 11 & 15 & 0 \\
\hline Homovanillic acid & 15 & 0 & 0 & 0 & 0 \\
\hline 3-Guaiacylpropanoic acid & 74 & 16 & 11 & 0 & 24 \\
\hline 1-Guaiacylethanol & 81 & 0 & 11 & 29 & 0 \\
\hline Dihydroconiferyl alcohol & 422 & 560 & 11 & 29 & 14 \\
\hline 1-Guaiacyl-1-hydroxyacetone & 81 & 32 & 11 & 0 & 0 \\
\hline Other guaiacyl compounds & 118 & 64 & 88 & 87 & 20 \\
\hline Syringol & 0 & 0 & 770 & 1088 & 136 \\
\hline 4-Methylsyringol & 0 & 0 & 165 & 493 & 0 \\
\hline 4-Ethylsyringol & 0 & 0 & 99 & 406 & 14 \\
\hline 4-Propylsyringol & 0 & 0 & 22 & 87 & 0 \\
\hline 4-Propenylsyringols ( 3 isomers) & 0 & 0 & 22 & 116 & 0 \\
\hline Syringaldehyde & 0 & 0 & 22 & 290 & 0 \\
\hline Acetosyringone & 0 & 0 & 88 & 203 & 19 \\
\hline Propiosyringone & 0 & 0 & 0 & 73 & 0 \\
\hline Syringylacetone & 0 & 0 & 66 & 276 & 22 \\
\hline 1-Hydroxy-1-syringylacetone & 0 & 0 & 11 & 87 & 0 \\
\hline Other syringyl compounds & 0 & 0 & 55 & 116 & 24 \\
\hline 1,2,4-Benzenetriol & 0 & 0 & 0 & 0 & 61 \\
\hline Hydroquinone & 178 & 328 & 440 & 450 & 102 \\
\hline 2-Methylhydroquinone & 52 & 40 & 176 & 174 & 46 \\
\hline Catechol & 1628 & 1280 & 1342 & 1175 & 146 \\
\hline 3-Methylcatechol & 104 & 136 & 77 & 102 & 0 \\
\hline 4-Methylcatechol & 363 & 240 & 407 & 334 & 31 \\
\hline 4-Ethylcatechol & 111 & 104 & 198 & 145 & 7 \\
\hline 3-Methoxycatechol & 0 & 0 & 220 & 348 & 73 \\
\hline 3-(2,3-Dihydroxyphenyl)-propanoic acid & 59 & 88 & 407 & 319 & 20 \\
\hline Other catechol compounds & 89 & 56 & 66 & 131 & 31 \\
\hline
\end{tabular}

Low PAH content of the liquid products was ensured, as the concentrations of the 16 EPA PAH compounds (naphthalene, acenaphtylene, asenaphthene, fluorine, phenanthrene, anthracene, fluoranthene, pyrene, bentso(a)anthracene, chrysene, bentzo(b)fluoranthene, bentzo(k)fluoranthene, bentzo(a)pyrene, indeno(1,2,3-cd)pyrene, dibentzo(a,h) anthracene and bentzo(g,h,i)perylene) analyzed in the liquids were all below detetion limit $\left(<0.1 \mathrm{mg} \mathrm{L}^{-1}\right)$ apart from the concentration of $0.4 \mathrm{mg} \mathrm{L}^{-1}$ naphthalene in FR-BL being very low in compared with those reported in other 
publications (e.g., Fagernäs et al. [19]). The total concentrations of PAHs were $<0.1 \mathrm{mg} \mathrm{L}^{-1}$ except in FR-BL (0.4 $\left.\mathrm{mg} \mathrm{L}^{-1}\right)$.

\section{Pesticidal Effects of the Liquids on Target Species}

The willow-based pyrolysis liquid (WI-PL) was the most effective repellent against the snails in all concentrations tested, followed by WH-PL, PB-PL, and FR-PL. When used at $10 \%$ concentration $(\mathrm{v} / \mathrm{v})$, all pyrolysis liquids induced a clear repellent influence on snails $(\mathrm{p}<0.01)$ (Fig. 1). WI-PL was as effective as the commercial repellent BioPlantella $(\mathrm{p}=1.000)$, while the repellent impact of WH-PL, PB-PL, and FR-PL was $76 \%, 61 \%$, and $53 \%$ of that of BioPlantella $(\mathrm{p}<0.05)$. At lower concentrations $(1 \% \mathrm{v} / \mathrm{v})$ there were more distinct differences between the products. For example, the repellent effect of WI-PL differed significantly from that of FR-PL and PB-PL ( $p=0.034, p=0.012$, respectively) and there were no differences between the repellent impact of the inert control, WH-PL, PB-PL, and FR-PL (1\% v/v) ( $p>0.05$ in each case) (Fig. 1). HTC-L had no repellent effect on snails even at the $20 \%$ and $10 \%$ concentrations $(\mathrm{v} / \mathrm{v})(\mathrm{p}=0.919)$.

The herbicidal effect of liquids was tested using turnip rape as the test species. In the control spirals receiving water only, the germination of seeds was $>80 \%$ during the first 7 days, and the proportion of dead seedlings between 7 and 14 days was only $2.8 \%$. Pesticide controls sprayed with MCPA and Cooper eliminated 91.4 and $89.6 \%$ of seedlings, respectively. At $100 \%$ concentration, all pyrolysis liquids showed a

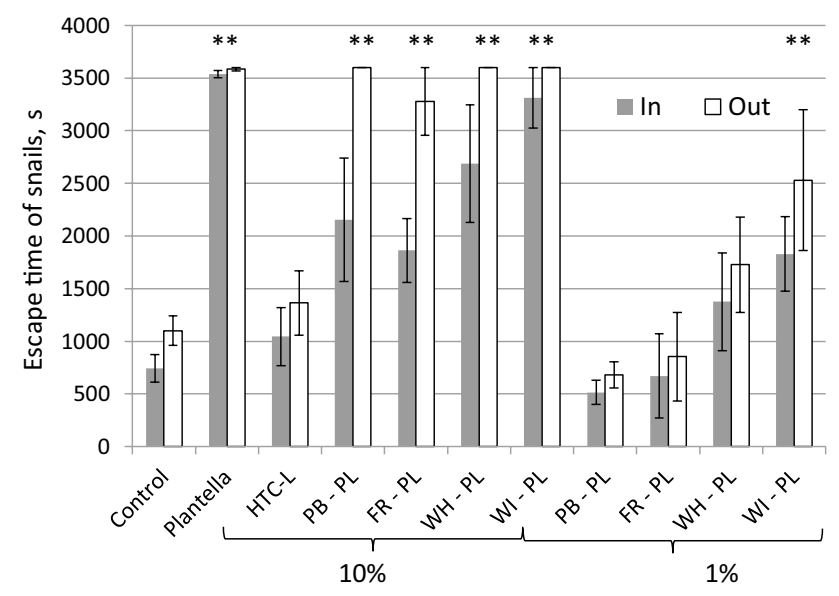

Fig. 1 Escape time (s) of snails from rings treated with $10 \%(\mathrm{v} / \mathrm{v})$ hydrothermal carbonization liquid (HTC-L) based on willow, slow pyrolysis liquids (10 and $1 \%$ concentrations, v/v) based on pine bark (PB-PL), forest residues (FR-PL), wheat straw (WH-PL), and willow (WI-PL), commercial repellent (Plantella), and control rings (=without additions) after $60 \mathrm{~min}$ exposure. $\mathrm{In}=$ snail located on the rim of the ring, Out $=$ snail outside the ring. ${ }^{*}$ Significant difference $(\mathrm{p}<0.01)$ compared with control clear herbicidal effect on turnip rape seedlings, eliminating $82.3-92.5 \%$ of seedlings (significance to control $\mathrm{p}<0.01$ in all cases, Mann-Whitney) (Table 4). WH-PL and WI-PL were as effective as the MCPA ( $\mathrm{p}=0.862$ in both cases) and Cooper controls $(\mathrm{p}=0.684)$. At $40 \%$ concentration $(\mathrm{v} / \mathrm{v})$, there were clear differences between products. The effect of WI-PL was still comparable to that of the herbicide controls, as $97.3 \%$ of seedlings died, while WH-PL and FR-PL eliminated $70.2 \%$ and $65.0 \%$ of seedlings, respectively (significance to control WH-PL: $\mathrm{p}<0.01$, FR-PL: $\mathrm{p}<0.05$ ). The effect of PB-PL was significantly lower than that of the other slow pyrolysis liquids, as it eliminated only $23.5 \%$ of seedlings (significance to control and all other liquids: $\mathrm{p}<0.05)$. In more dilute concentrations $(<40 \%)$ the differences were even more evident, with WI-PL always being the most effective, followed by WH-PL, FR-PL, and PB-PL (Table 4). HTC-L had no herbicidal effect on seedlings even at $100 \%$ concentration.

At $100 \%$ concentration, all pyrolysis liquids eliminated 98-100\% of aphids (in all cases $\mathrm{p}<0.05$ compared with control) (Fig. 2) and no differences between the liquids were observed $(\mathrm{p}=1.000)$. However, $100 \%$ HTC-L had no effect on aphid survival or condition $(\mathrm{p}=1.000)$. At $50 \%$ concentration, the effect of all slow pyrolysis liquids differed from that of the water control (in all cases $\mathrm{p}<0.05$ ), but there were also clear differences between products. For example, WH-PL and WI-PL were still as effective as the Sumi-Alpha control ( $p=0.990$ compared with Sumi-Alpha), eliminating $>90 \%$ of aphids, while PB-PL and FR-PL eliminated $59 \%$ and $67 \%$ of aphids, respectively (compared with SumiAlpha: $p<0.001 \mathrm{p}=0.039$, respectively) (Fig. 2). In $20 \%$ concentration, WH-PL and WI-PL were still as effective in eliminating aphids as the commercial product Sumi-Alpha $(\mathrm{p}=0.855, \mathrm{p}=0.758$, respectively). The insecticidal effect of WH-PL decreased to below $50 \%$ at $15 \%$ concentration, while WI-PL still had almost $90 \%$ insecticidal effect on aphids (Fig. 2).

Regression analysis showed a correlation between acetic acid concentration of the slow pyrolysis liquids and time taken for snails to escape outside the rings $\left(R^{2}=0.913\right.$, $\mathrm{p}=0.045)$. However, no correlation was found between the other individual compounds of liquids and observed efficacy in controlling snails, aphids, or weeds (step-wise regression analysis, $\mathrm{p}>0.05$ ).

\section{Pesticidal Activity in Relation to Specific Compounds in Slow Pyrolysis Liquids}

The concentrations of organic compounds in the final HTC liquid remained very low and it had no pesticidal effect on target organisms. Concentrations of organic compounds in slow pyrolysis liquids varied between 12.8 and $30.4 \%$ (Table 4) and might explain some, but not all, of the 
Table 4 Percentage (\%) of dead, healthy, and damaged turnip rape seedlings after 7 days of exposure to various concentrations of hydrothermal carbonization liquid (HTC-L) based on willow, slow pyrolysis liquids based on pine bark (PB-PL), forest residues (FR-PL), wheat straw (WH-PL), and willow (WI-PL), the commercial herbicides MCPA and cooper (active controls) and water (inert control$\left.\mathrm{H}_{2} \mathrm{O}\right)($ mean $\pm \mathrm{SE})$

\begin{tabular}{|c|c|c|c|c|c|}
\hline Product & Conc., $\%$ & $\mathrm{OMC} \%$ & Dead seedlings $\%$ & Healthy seedlings $\%$ & Damaged seedlings $\%$ \\
\hline Control- $\mathrm{H}_{2} \mathrm{O}$ & 100 & 0 & $2.8 \pm 1.3$ & $85.8 \pm 2.3$ & $11.3 \pm 2.4$ \\
\hline Control-MCPA & 0.5 & n.d. & $91.4 \pm 3.8$ & $6.8 \pm 3.0$ & $1.9 \pm 1.1$ \\
\hline Control-cooper & 25 & n.d. & $89.6 \pm 8.0$ & $5.9 \pm 5.0$ & $4.5 \pm 4.5$ \\
\hline HTC-L & 100 & 4.0 & $7.7 \pm 3.1^{\mathrm{b}, * *, \mathrm{c}, * *}$ & $78.0 \pm 7.7^{\mathrm{b}, * *, \mathrm{c}, * *}$ & $14.3 \pm 4.9$ \\
\hline PB-PL & 100 & 12.8 & $82.6 \pm 13.3^{\mathrm{a}, * *}$ & $8.8 \pm 4.8^{\mathrm{a}, * *}$ & $8.6 \pm 8.6$ \\
\hline FR-PL & 100 & 18.5 & $82.3 \pm 8.4^{\mathrm{a}, * *}$ & $3.9 \pm 2.3^{\mathrm{a}, * *}$ & $13.7 \pm 7.0$ \\
\hline WH-PL & 100 & 25.4 & $92.5 \pm 4.4^{\mathrm{a}, * *}$ & $5.8 \pm 3.9^{\mathrm{a}, * *}$ & $1.7 \pm 1.7$ \\
\hline WI-PL & 100 & 30.4 & $92.3 \pm 4.5^{\mathrm{a}, * *}$ & $6.0 \pm 3.9^{\mathrm{a}, * *}$ & $1.8 \pm 1.8$ \\
\hline HTC-L & 40 & 1.6 & $2.6 \pm 1.5^{\mathrm{b}, * *, \mathrm{c}, * *}$ & $94.7 \pm 2.3^{\mathrm{b}, * *, \mathrm{c}, * *}$ & $2.8 \pm 2.8$ \\
\hline PB-PL & 40 & 5.1 & $23.5 \pm 17.2^{\mathrm{a}, *}$ & $68.9 \pm 18.2^{\mathrm{a}, *}$ & $7.6 \pm 2.4$ \\
\hline FR-PL & 40 & 7.4 & $65.0 \pm 7.5^{\mathrm{a}, * *}$ & $21.0 \pm 5.8^{\mathrm{a}, * *}$ & $14.0 \pm 8.8$ \\
\hline WH-PL & 40 & 10.2 & $70.2 \pm 10.1^{\mathrm{a}, * *}$ & $25.1 \pm 8.5^{\mathrm{a}, * *}$ & $4.7 \pm 3.3$ \\
\hline WI-PL & 40 & 12.2 & $97.3 \pm 0.7^{\mathrm{a}, * *}$ & $0.0 \pm 0.0^{\mathrm{a}, * *}$ & $2.7 \pm 1.6$ \\
\hline HTC-L & 30 & - & n.d. & n.d. & n.d. \\
\hline PB-PL & 30 & - & n.d. & n.d. & n.d. \\
\hline FR-PL & 30 & 5.6 & $21.2 \pm 7.9^{\mathrm{b}, * *, \mathrm{c} * *}$ & $57.4 \pm 17.5^{\mathrm{a}, *, \mathrm{~b} * *, \mathrm{c}, * *}$ & $21.4 \pm 11.6$ \\
\hline WH-PL & 30 & 7.6 & $71.6 \pm 18.5^{\mathrm{a}, * *}$ & $5.6 \pm 5.6^{\mathrm{a}, * *}$ & $22.8 \pm 13.8$ \\
\hline WI-PL & 30 & 9.1 & $79.2 \pm 8.3^{\mathrm{a}, * *}$ & $2.3 \pm 2.3^{\mathrm{a}, * *}$ & $18.5 \pm 8.8$ \\
\hline HTC-L & 20 & - & n.d. & n.d. & n.d. \\
\hline PB-PL & 20 & - & n.d. & n.d. & n.d. \\
\hline FR-PL & 20 & - & n.d. & n.d. & n.d. \\
\hline WH-PL & 20 & 5.1 & $39.7 \pm 12.9^{\mathrm{a}, *, \mathrm{~b}, * *, \mathrm{c}, * *}$ & $44.1 \pm 9.7^{\mathrm{a}, *, \mathrm{~b}, * *, \mathrm{c} * *}$ & $16.2 \pm 3.7$ \\
\hline WI-PL & 20 & 6.1 & $56.8 \pm 13.5^{\mathrm{a}, * *, \mathrm{~b}, * *, \mathrm{c}, * *}$ & $29.8 \pm 9.9^{\mathrm{a}, * *, \mathrm{~b}, * *, \mathrm{c}, * *}$ & $13.4 \pm 6.7$ \\
\hline
\end{tabular}

OMC \% Organic matter concentration of the dilution (\%)

Different letters indicate significant difference $\left({ }^{*} \mathrm{p}<0.05\right.$ or $\left.* * \mathrm{p}<0.01\right)$ of treatment compared with the $\mathrm{H}_{2} \mathrm{O}\left({ }^{\mathrm{a}}\right)$, MCPA $\left({ }^{\mathrm{b}}\right)$ and Cooper $\left({ }^{\mathrm{c}}\right)$ controls

Fig. 2 Percentages of dead (black column), knockdown (grey), and live (white) aphids dipped in 100, 50, 40, 25, 20, 15,10 or $5 \%$ dilutions of slow pyrolysis liquids based on pine bark (PB-PL), forest residues (FR-PL), wheat straw (WH-PL), and willow (WI-PL), hydrothermal carbonization (HTC) liquid based on willow (HTC-L), active control herbicide (SumiAlpha $0.5 \mathrm{mg} \mathrm{L}^{-1}$ ) or water only. Different letters denote significant difference $(\mathrm{p}<0.05)$ compared with water (a) or Sumi-Alpha (b). A dilution eliminating $>80 \%$ of aphids was carried on for testing at the next dilutions

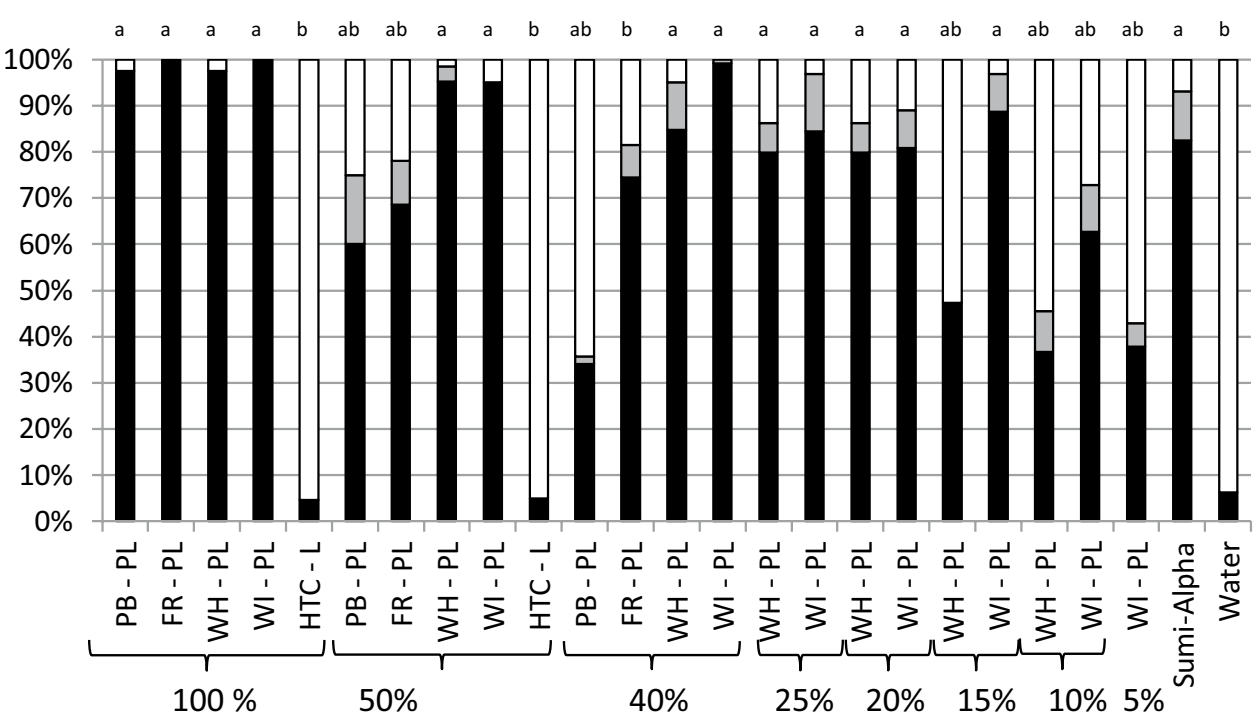


observed responses on target organisms. For example, the $40 \%$ dilution of WH-PL contained $10.2 \%$ organic matter and eliminated $70 \%$ of rape seedlings and $84 \%$ of aphids, while the $40 \%$ dilution of PB-PL, which contained $5.1 \%$ organic matter, eliminated only $23 \%$ and $34 \%$ of aphids, respectively, i.e., the difference in effect was greater than the variation in organic matter content of the solutions (Table 4).

The content of acids, resulting mainly from high concentrations of acetic acid (Table 2), was most probably the main reason for the higher pesticidal activity of willowbased pyrolysis liquid (WI-PL) compared with the other liquids (PB-PL, FR-PL, WH-PL). Acetic acid has long been applied in plant protection. It is an approved active substance in Europe and listed as a biopesticide in the USA $[36,37]$. The acetic acid content of WI-PL was about $16.2 \%$ $(w / v)$, whereas that of PB-PL was only around a quarter of that level (4.4\%). Acetic acid has been shown to be one of the strongest termiticides in pyrolysis liquid (wood vinegar) [10]. According to Kim et al. [38], most of the contact poison properties of pyrolysis liquid (liquid smoke) are explained by the content of acetic acid, which can damage the cuticle permeability of an insect, causing it to die. Other volatile fatty acids such as formic acid, valeric acid, and propanoic acid have also been shown to have termiticidal activity [12]. In the present study, the concentration of propanoic acid was higher in WI-PL and WH-PL than in the softwood-derived liquids, which contained similar or even higher concentrations of formic acid.

In addition to acetic acid, other major volatiles detected included methanol, furfural, hydroxyacetone(1-hydroxy2-propanone), formic acid, and 1-hydroxy-2-butanone (Table 2). Among these, the concentration of methanol (1.5-2\%) did not vary significantly between the slow pyrolysis liquids tested. Methanol does not repel snails [10] and it has not been used as a pesticide. However, furfural has a long tradition in plant protection, where it has been used due to its antifungal and nematicidal activity [39]. In the present samples, the overall furfural concentrations were relatively low and no clear link (step-wise regression analysis: $p>0.05$ ) was found between the responses of target organisms and furfural concentration in the liquids. In fact, among the pyrolysis liquids PB-PL was the least effective as a pesticide although it contained the highest furfural concentrations (Table 2). This is an important observation for commercialization of slow pyrolysis liquids, as furfural is not approved as an active pesticide substance in Europe [37]. Of the slow pyrolysis liquids tested, PB-PL $\left(8.2 \mathrm{~g} \mathrm{~L}^{-1}\right)$ contained the lowest concentrations of hydroxyacetone, but there were no significant differences between the other liquids (15-19 $\mathrm{g} \mathrm{L}^{-1}$ ) (Table 2). Both hydroxyacetone and 1-hydroxy-2-butanone have been reported to be safe food flavoring agents [40] and no toxicity values for insects or weeds are available in scientific databases. Overall, it can be presumed that, because of its high content in pyrolysis liquids, acetic acid is mainly responsible for the pesticidal activity on soft-bodied pests such as aphids and snails. Due to its high acidity, pyrolysis liquid has also a strong herbicidal activity when used in high concentrations. Our results suggests that the potential effectivity and required dose of various slow pyrolysis liquids, when used against soft-bodied insects and broadleaf weeds, can be evaluated according to the total content of acids in the product (Table 2).

Various phenols found in slow pyrolysis liquids have been reported to have pesticidal activities, for example against termites [12]. Most of these phenols are produced during pyrolysis of lignin $\left(>375^{\circ} \mathrm{C}\right)$. As the liquids in the present study were collected below $280^{\circ} \mathrm{C}$, the concentration of phenols was quite low $(<1 \%)$ compared with that reported by e.g., Yatagai et al. [12] (>1.5\%). The concentration of phenols, especially syringol derivatives, was highest in WI-PL followed by WH-PL, which were also the most effective pesticides among the liquids tested. However, the low overall concentration of phenolic compounds makes it reasonable to believe that these compounds explain only part of the observed responses.

In earlier work, we examined the repellent effect of various constituents of birch (Betula sp.)-derived pyrolysis liquid on snails [10] but in that study the liquid contained significantly higher amounts of PAH compounds (21-290 $\mathrm{mg} \mathrm{kg}^{-1}$ ) and it was therefore concluded that the observed repellent impact on snails might be partly due to these PAH substances. In addition, Orihashi et al. [41] found that wood vinegar (without the less-soluble tar fraction) did not reduce barking damage by vole (Clethrionomys rufocanus bedfordiae) and concluded that the tar fraction is crucial in deterring voles. Also Hossain et al. [11] concludes PAHs likely to be the principal compounds responsible for the observed insecticidal activity of pyrolysis bio-oils. In the present study, the concentrations of 16 EPA PAHs in the slow pyrolysis liquids were $<0.1 \mathrm{mg} \mathrm{L}^{-1}$, and therefore $\mathrm{PAH}$ substances can not explain the observed efficacy of the slow pyrolysis liquids against snails, aphids, and broadleaf weeds.

Slow pyrolysis and HTC are both promising technologies for producing high quality biochar for various purposes [42, 43]. In HTC, biomass is typically processed at approximately $10-20 \%$ consistency, i.e. in a high amount of water in the process. In this study, the liquid fraction from willow was recycled four times in the HTC process to make it more concentrated for the plant protection tests. However, the dry matter content of the willow-water slurry was only $4 \%$ in each run. Due to dilution effect, the concentration of organic compounds in the final HTC liquid remained very low and no pesticidal effects on target organisms were seen. Consequently, dilute HTC liquids from plant biomass processing as such are not suitable for pesticides. However, temperature-separated slow pyrolysis 
liquids proved to be suitable as pesticides. To achieve sufficiently concentrated liquids, attention has to be paid to feedstock dryness and quality. By collecting slow pyrolysis liquids before the main lignin degradation phase, i.e., below $280{ }^{\circ} \mathrm{C}$, it is possible to produce high quality slow pyrolysis liquids with low phenol and PAH concentrations to be used e.g., in plant protection according to IPM practices. However, it is especially challenging to commercialize the liquid fractions from slow pyrolysis due to extensive and costly determination of their detailed composition required during registration of active substances according to the REACH and plant protection product regulations in the EU $[4,8]$.

\section{Conclusions}

The liquid by-products from thermochemical conversion technologies are currently under-utilized or disposed. To increase the economic feasibility of these technologies, better exploitation of the liquid fraction is required. In this study, liquids from slow pyrolysis and hydrothermal carbonization were analyzed and tested in plant protection. Willow-derived slow pyrolysis liquid was the most effective pesticide against test pests (snails, aphids, broadleaf weeds). The repellent effect of the slow pyrolysis liquids was due to the combined chemical constituents rather than a single compound, confirming previous findings. However, in most cases the total acid and acetic acid concentration of the slow pyrolysis liquids could be used as an indicator of their usability and efficiency in pest control. Selection of raw material and technology will determine the quality of liquids and potential to commercialize these products.

Acknowledgements Open access funding provided by Natural Resources Institute Finland (LUKE). Prof. Sylvia Larsson and $\mathrm{Mr}$. Gunnar Kalén from SLU (Swedish University of Agricultural Sciences) are thanked for providing the raw materials for the slow pyrolysis and HTC experiments. We would also like to thank Mr. Taisto Raussi for practical advice on upgrading the pyrolysis liquids. This project received funding from the European Union's Horizon 2020 Research and Innovation Programme under Grant Agreement No. 637020-MOBILE FLIP.

Author Contributions KR, KT and IL conceived and designed research. $\mathrm{KN}, \mathrm{HW}$ and $\mathrm{AK}$ conducted process experiments for liquid production and IL \& KT conducted the plant protection experiments. IL and KT conducted experiments. KN, HW and AK contributed to liquid analysis. $\mathrm{MH}$ analyzed data. $\mathrm{MH}$ wrote the first version of manuscript and all authors read, commented and approved the manuscript.

\section{Compliance with Ethical Standards}

Conflict of interest The authors declare that they have no conflict of interest.

OpenAccess This article is distributed under the terms of the Creative Commons Attribution 4.0 International License (http://creativeco mmons.org/licenses/by/4.0/), which permits unrestricted use, distribution, and reproduction in any medium, provided you give appropriate credit to the original author(s) and the source, provide a link to the Creative Commons license, and indicate if changes were made.

\section{References}

1. Wilk, M., Magdziarz, A.: Hydrothermal carbonization, torrefaction and slow pyrolysis of Miscanthus giganteus. Energy 149, 1292-1304 (2017)

2. Libra, J.A., Ro, K.S., Kammann, C., Funke, A., Berge, N.D., Neubauer, Y., Titirici, M.-M., Fühner, C.F., Bens, O., Kern, J., Emmerich, K.H.: Hydrothermal carbonization of biomass residuals: a comparative review of the chemistry, processes and applications of wet and dry pyrolysis. Biofuels 2, 89-124 (2011)

3. Sjöström, E.: Wood Chemistry, Fundamentals and Applications, 2nd edn., pp. 234-235. Academic Press, San Diego (1993)

4. Hoekman, S.K., Broch, A., Robbins, C.: Hydrothermal carbonization (HTC) of lignocellulosic biomass. Energy Fuels 25, 1802-1810 (2011)

5. Fagernas, L., Kuoppala, E., Tiilikkala, K., Oasmaa, A.: Chemical composition of birch wood slow pyrolysis products. Energy Fuels 26, 1275-1283 (2012)

6. Keskinen, R., Hyväluoma, J., Wikberg, H., Källi, A., Salo, T., Rasa, K.: Possibilities of using liquids from slow pyrolysis and hydrothermal carbonization in acidification of animal slurry. Waste Biomass Valor. 9, 1429-1433 (2017)

7. Cao, L., Yu, I.K.M., Liu, Y., Ruan, X., Tsang, D.C.W., Hunt, A.J., Ok, Y.S., Song, H., Zhang, S.: Lignin valorization for the production of renewable chemicals: state-of-the-art review and future prospects. Bioresour. Technol. 269, 465-475 (2018)

8. Rasrendra, C.B., Girisuta, B., Van de Bovenkamp, H.H., Winkelman, J.G.M., Leijenhorst, E.J., Venderbosch, R.H., Windt, M., Meier, D., Heeres, H.J.: Recovery of acetic acid from an aqueous pyrolysis oil phase by reactive extraction using trin-octylamine. Chem. Eng. J. 176-177, 244-252 (2011)

9. Zilnik, L.F., Jazbinšek, A.: Recovery of renewable phenolic fraction from pyrolysis oil. Sep. Purif. Technol. 86, 157-170 (2012)

10. Hagner, M., Kuoppala, E., Fagernäs, L., Tiilikkala, K., Setälä, H.: Using the copse snail Arianta arbustorum (Linnaeus) to detect repellent compounds and the quality of wood vinegar. Int. J. Environ. Res. 9, 53-60 (2015)

11. Hossain, M.M., Scott, M.I., McGarvey, B.D., Conn, K., Ferrante, L., Berruti, F., Briens, C.: Insecticidal and anti-microbial activity of bio-oil derived from fast pyrolysis of lignin, cellulose, and hemicellulose. J. Pest. Sci. 88, 171-179 (2015)

12. Yatagai, E., Nishimoto, M., Hori, K., Ohira, T., Shibata, A.: Termiticidal activity of wood vinegar, its components and their homologues. J. Wood Sci. 48, 338-342 (2002)

13. Tiilikkala, K., Fagernäs, L., Tiilikkala, J.: History and use of wood pyrolysis liquids as biocide and plant protection product. Open Agric. J. 4, 111-118 (2010)

14. Lindqvist, I., Lindqvist, B., Tiilikkala, K., Hagner, M., Penttinen, O.-P., Pasanen, T., Setälä, H.: Birch tar oil is an effective mollusc repellent: field and laboratory experiments using 
Arianta arbustorum (Gatroboda, Helicidae) and Arion lusitanicus (Gastroboda, Arionidae). Agric. Food Sci. 19, 1-12 (2010)

15. Ibrahim, D., Kassim, J., Sheh-Hong, L., Rusli, W.: Efficacy of pyroligneous acid from Rhizophora apiculate on pathogenic Candida albicans. J. Appl. Pharm. Sci. 3, 7-13 (2013)

16. Oramahi, H.A., Yoshimura, T.: Antifungal and antitermitic activities of wood vinegar from Vitex pubescens Vahl. J. Wood Sci. 59, 344-350 (2013)

17. Kårlund, A., Salminen, J.P., Koskinen, P., Ahern, J.R., Karonen, M., Tiilikkala, K., Karjalainen, R.O.: Polyphenols in strawberry (Fragaria $\times$ ananassa) leaves induced by plant activators. J. Agric. Food Chem. 62, 4592-4600 (2014)

18. Abdel-Shafy, H.I., Mansour, M.S.M.: A review on polycyclic aromatic hydrocarbons: source, environmental impact, effect on human health and remediation. Egypt. J. Petrol. 25, 107-123 (2016)

19. Fagernäs, L., Kuoppala, E., Simell, P.: Polycyclic aromatic hydrocarbons in birch wood slow pyrolysis products. Energy Fuels 26, 6960-6970 (2012)

20. Fagernäs, L., Kuoppala, E., Arpiainen, V.: Composition, utilization and economic assessment of torrefaction condensates. Energy Fuels 29, 3134-3142 (2015)

21. Wikberg, H., Grönqvist, S., Niemi, P., Mikkelson, A., Siika-Aho, M., Kanerva, H., Käsper, A., Tamminen, T.: Hydrothermal treatment followed by enzymatic hydrolysis and hydrothermal carbonization as means to valorise agro- and forest-based biomass residues. Bioresour. Technol. 235, 70-78 (2017)

22. Lindfors, C., Kuoppala, E., Oasmaa, A., Solantausta, Y., Arpiainen, V.: Fractionation of bio-oil. Energy Fuels 28, 5785-5791 (2014)

23. Borrega, M., Niemelä, K., Sixta, H.: Effect of hydrothermal treatment intensity on the formation of degradation products from birch wood. Holzforschung 67, 871-879 (2013)

24. Niemelä, K.: Low-molecular-weight organic compounds in birch kraft black liquor. Ann. Acad. Sci. Fenn. Ser. A II, Chemica 229, 142 (1990)

25. Raboud, C.: Age determination of Arianta arbustorum (L.) pulmonata based growth breaks and inner layers. J. Mollusc. Stud. 53, 243-247 (1986)

26. Operating and Maintenance Instructions for Jacobsen Germination Table Type 5000-5300 Version E/50-53/02-2001. http://rumed .de/wp-content/uploads/2015/08/E_50-53_02-2001.pdf (2001)

27. Bugge, G.: Industrie der Holzdestillations-Produkte, 216. Verlag von Theodor Steinkopff, Dresden (1927)

28. Branca, C., Giudicianni, P., Di Blasi, C.: GC/MS characterization of liquids generated from low-temperature pyrolysis of wood. Ind. Eng. Chem. Res. 42, 3190-3202 (2003)

29. Mathew, S., Zakaria, Z.A.: Pyroligneous acid-the smoky acidic liquid from plant biomass. Appl. Microbiol. Biotechnol. 99, 611622 (2015)

30. Ingram, L., Mohan, D., Bricka, M., Steele, P., Strobel, D., Crocker, D., Mitchell, B., Mohammad, J., Cantrell, K., Pittman, C.U.:
Pyrolysis of wood and bark in an auger reactor: physical properties and chemical analysis of the produced bio-oils. Energy Fuels 22, 614-662 (2008)

31. Oasmaa, A., Kuoppala, E., Solantausta, Y.: Fast pyrolysis of forestry residue. 2. Physicochemical composition of product liquid. Energy Fuels 17, 433-443 (2003)

32. Olejniczak, A., Kucinska, A., Cyganiuk, A.W., Lukaszewicz, J.P.: Effect of Salix viminalis pyrolysis derived antioxidants on oxidative stability of diesters and diester-poly- $\alpha$-olefin mixtures. Ind. Eng. Chem. Res. 51, 5117-5123 (2012)

33. Pakkanen, H., Alén, R.: Alkali consumption of aliphatic carboxylic acids during alkaline pulping of wood and nonwood feedstocks. Holzforschung 67, 643-650 (2013)

34. Snook, M.E., Mason, P.F., Arrendale, R.F., Chortyk, O.T.: Capillary gas chromatography of dihydroxybenzoic,-phenylacetic and -phenylpropionic acids. J. Chromatogr. A 324, 141-151 (1985)

35. Burlingame, R., Chapman, P.J.: Catabolism of phenylpropionic acid and its 3-hydroxy derivative by Escherichia coli. J. Bacteriol. 155, 113-121 (1983)

36. EPA 2017: Biopesticides Fact Sheet for Acetic Acid. United States Environmental Protection Agency https://www3.epa.gov/pesti cides/chem_search/reg_actions/registration/fs_PC-044001_01Mar-01.pdf

37. EU. Pesticides Database: 2017. http://ec.europa.eu/food/plant/ pesticides/eu-pesticides-database/public/?event=activesubstance .selection\&language $=\mathrm{EN}$

38. Kim, D.H., Seo, H.E., Lee, S.C., Lee, K.Y.: Effects of wood vinegar mixed with insecticides on the mortalities of Nilaparvata lugens and Laodelphax striatellus (Homoptera: Delphacidae). Anim. Cells Syst. 12, 47-52 (2008)

39. Hensley, J., Burger, G.: Nematicidal properties of furfural and the development for nematode control in various crops for the United States markets. J. Nematol. 38, 274 (2006)

40. EU. EU Lists of Flavourings. https://webgate.ec.europa.eu/foods _system/main/index.cfm (2017)

41. Orihashi, K., Kojima, Y., Terazawa, M.: Deterrent effect of rosin and wood tar against barking by the gray-sided vole (Clethrionomys rufocanus bedfordiae). J. For. Sci. 6, 191-196 (2001)

42. Titirici, M.-M., Antonietti, M.: Chemistry and materials options of sustainable carbon materials made by hydrothermal carbonization. Chem. Soc. Rev. 39, 103-116 (2010)

43. Kambo, H.S., Dutta, A.: A comparative review of biochar and hydrochar in terms of production, physico-chemical properties and applications. Renew. Sust. Energy Rev. 45, 359-378 (2015)

Publisher's Note Springer Nature remains neutral with regard to jurisdictional claims in published maps and institutional affiliations.

\section{Affiliations}

\section{Marleena Hagner $^{1,2} \cdot$ Kari Tiilikkala $^{1} \cdot$ Isa Lindqvist ${ }^{1} \cdot$ Klaus Niemelä $^{3} \cdot$ Hanne Wikberg $^{3,4} \cdot$ Anssi Källi $^{3} \cdot$ Kimmo Rasa $^{1}$}

1 Natural Resources Institute Finland (Luke), 31600 Jokioinen, Finland

2 Faculty of Biological and Environmental Sciences, Ecosystems and Environment Research Programme, University of Helsinki, 15140 Lahti, Finland
3 VTT Technical Research Centre of Finland Ltd, P.O. Box 1000, 02044 Espoo, Finland

4 Present Address: Fortum Power and Heat Ltd, P.O. Box 100, 00048 Espoo, Finland 